\title{
Analysis on Correlation between Resistin-420C/G Polymorphism and Type 2 Diabetes Mellitus Macroangiopathy in Han Population of Northeast China*
}

\author{
Bingxue Qi*, Ma Yan*, Yadong Sun\# \\ Department of Endocrinology, People's Hospital of Jilin Province, Changchun, China \\ Email: "qibxmm@163.com
}

How to cite this paper: Qi, B.X., Yan, M. and Sun, Y.D. (2017) Analysis on Correlation between Resistin-420C/G Polymorphism and Type 2 Diabetes Mellitus Macroangiopathy in Han Population of Northeast China. Journal of Biosciences and Medicines, 5, 17-23.

https://doi.org/10.4236/jbm.2017.512003

Received: September 3, 2017

Accepted: November 18, 2017

Published: November 21, 2017

\begin{abstract}
Objective: To study the allelic and genotypic frequency distribution of RETN-420C/G single nucleotide polymorphisms (SNPs) and its relationship with type 2 diabetes mellitus (T2DM) complicated with macroangiopathy in Han population of northeast China. Methods: The genotypes and their frequencies of a total of 180 cases, including 60 cases of T2DM complicated with macroangiopathy, 60 cases of simple T2DM and 60 cases of normal control (ND), were measured by PCR-RFLP. Results: The allelic frequencies and simple CC/GC + GG genotype in T2DM complicated with macroangiopathy group were significant different compared with ND group $(P<0.01)$. The allelic frequencies and CC/GC + GG genotype in T2DM complicated with macroangiopathy group were significant different compared with T2DM group $(P<0.05)$. The GC + GG genotype in T2DM complicated with macroangiopathy group was significantly higher than that in T2DM group $(P<0.05)$. Conclusion: The RETN-420C/G polymorphism has a correlation with the occurrence of T2DM complicated with macroangiopathy in Han population of northeast China.
\end{abstract}

\section{Keywords}

Type 2 Diabetes Mellitus, Resistin, Gene Polymorphism, Macroangiopathy, Polymerase Chain Reaction

\section{Introduction}

Diabetes is one of the four major diseases that threaten human health. Diabetic

*These authors contributed equally to this work. 
macroangiopathy is the main chronic complication in patients with T2DM. The incidence and mortality of macrovascular events in patients with T2DM is $2-4$ times of non-diabetics. It is the main cause of death and disability in patients with T2DM. Clinical practice has proved: Not all the patients with T2DM always present macroangiopathy; it has obvious familial aggregation; the occurrence of macroangiopathy in patients with $\mathrm{T} 2 \mathrm{DM}$ is closely related to genetic background. Evidence-based medical practice, such as United Kingdom Prospective Diabetes Study (UKPDS) showed that: the pathogenesis of the occurrence of macroangiopathy in patients with T2DM is not completely consistent to T2DM; macroangiopathy also occurs in the patients with blood glucose, blood pressure and cholesterol under control; genetic factors play important role in the incidence of T2DM [1]. To explore the molecular mechanisms of T2DM patients and their occurrence of macroangiopathy, to determine the correlation between genetics and pathogenesis, to seek new ways of prevention and control, it has become the common focus attention of international endocrine and cardiovascular experts. In recent years, the study shows that: A protein, which is rich in cysteine, is associated with pancreatic resistance, and it is called the resistance element (resistin, RETN) [2]. At present, many scholars listed RETN gene and peroxisome proliferator-activated receptor (PPAR- $\gamma$ ) gene as candidate genes of macroangiopathy in patients with T2DM [3] [4] [5] [6] [7], But the research about their relations with macroangiopathy is not consistent. Especially, related studies have not reported about the relationship between the mutation of RETN gene and PPAR- $\gamma$ gene and T2DM complicated with macroangiopathy in ethnic groups of northeast China. This study aims to explore the relationship between the RETN-420C/G polymorphism and the occurrence of T2DM complicated with macroangiopathy in Han population of northeast China, to determine if it is the risk factor of the occurrence of T2DM complicated with macroangiopathy.

\section{Materials and Methods}

\subsection{Sample Source}

Cases of samples derived from the hospitalized patients with clinical diagnosis of T2DM in our department of endocrinology in January 2009-August 2010. A total of 120 cases were randomly divided into two subgroups: T2DM complicated with macroangiopathy group and simple T2DM group, with 60 cases in each group. T2DM complicated with macroangiopathy group, 53 - 69 years old, the average $(59.2+9.1)$ years of age, with 33 cases of men and 27 cases of women; Simple T2DM group, 50 - 65 years old, the average $(57.8 \pm 10.1)$ years of age, with 31 cases of men and 29 cases of women. In 1999, the WHO diagnostic criteria diagnosis of T2DM, concurrent big vascular lesions diagnostic criteria is as follows: 1) Lower limb vascular lesion: intermittent claudication, rest pain, loss of dorsalis pedis artery pulse, foot ischemic ulcers or gangrene, all confirmed by peripheral vascular ultrasound or peripheral vascular atherosclerosis occlusion; 2) Coronary heart disease (CHD): a history of typical angina pectoris or myo- 
cardial infarction and electrocardiogram behavior or by coronary angiography diagnosis; 3) Cerebrovascular disease: Hemiplegia or other focal cerebral symptoms, craniocerebral CT scan or MRI showed ischemia or hemorrhage. Not T2DM group (con group), with 60 cases of the normal samples derived from medical center health check-up people, 47 - 58 years old, the average (54.4 \pm 11.6) years of age, with 30 cases of men and 30 cases of women, Exclusion of T2DM, coronary heart disease, hyperlipidemia, hypertension, kidney disease, cerebrovascular disease and no family history of T2DM and hypertension. All the objects of this study are the Han people in northeast China. All the research objects were taken $5 \mathrm{ml}$ elbow venous blood.

\subsection{Main Reagents and Equipment}

Ascensia Breeze portable blood glucose meter and blood sugar test bought from Germany's bayer; OLYMPUS-AU5400 Automatic biochemical analyzer purchased from Japan Olympus company; Glycated hemoglobin A1c (HbA1c) ELISA kit and Hypersensitive c-reactive protein (hs-CRP) ELISA kit purchased from Shanghai Shriver biotechnology company. Insulin (INS) kit purchased from Shanghai Yuanye biotechnology company; Genomic DNA purification kit purchased from Shanghai Shriver biotechnology company; OLIGO192 DNA synthesizer Purchased from the United States Beckman company; ABI PRISM 310 genetic analyzer purchased from the United States PEABI company.

\subsection{DNA Preparation and PCR Amplification}

Put the $5 \mathrm{~mL}$ venous blood into ACD anticoagulant tube, separation, obtain the white blood cells, preparation of genomic DNA by the method of phenol-chloroform. According to the specific sequence of resistance gene design primers, the forward primer: 5'-GAGAAGTGGTCTTGCTCTG-3', the reverse primer: 5'-GGCTTGGCTAATAAGTCCC-3', Amplified fragment length is $412 \mathrm{bp}$. PCR amplification reagents, a total of $25 \mu \mathrm{L}$, cotain dNTP $5 \mathrm{nmol}$, Taq DNA polymerase $0.625 \mathrm{U}, \mathrm{MgCl}_{2} 50 \mathrm{nmol}$, forward and reverse primers each $10 \mathrm{pmol}$ and DNA template about $100 \mathrm{ng}$. The PCR reaction conditions: $94^{\circ} \mathrm{C}, 3 \mathrm{~min} ; 94^{\circ} \mathrm{C}$, $30 \mathrm{~s} ; 55^{\circ} \mathrm{C}, 30 \mathrm{~s} ; 72^{\circ} \mathrm{C}, 1 \mathrm{~min}$, a total of 35 loop; $72^{\circ} \mathrm{C}, 3 \mathrm{~min}$ after the end of time cycle.

\subsection{DNA Sequence Analysis}

Take $10 \mu \mathrm{L}$ amplification products, enzyme $4 \mathrm{~h}$ under $37^{\circ} \mathrm{C}$ by Ear Ienzyme $5 \mathrm{U}$. Cut enzyme product sample points in agarose gel electrophoresis, observation and radiography under ultraviolet light, Analysis of genotype. DNA sequencing performed by PRISM ABI 310 genetic analyzer.

\subsection{Statistical Analysis}

Using SPSS 11.5 statistical software for statistical analysis, Hardy Weinberg equilibrium and genotype compared by chi-square test. 


\section{Result}

\subsection{Enzyme Electrophoresis Results of RETN Gene PCR Products.}

It have obtained three genotypes after The Ear Ienzyme product electrophoresis: 1) The GG type: lacking of the Ear Ienzyme loci, Only have $412 \mathrm{bp}$ fragments after enzyme digestion. 2) The GG type: containing the Ear Ienzyme loci, it has obtained the two fragments of $126 \mathrm{bp}$ fragments and $286 \mathrm{bp}$ fragments after enzyme digestion. 3) The GC type: Miscellaneous type, it have obtained the three fragments of $126 \mathrm{bp}$ fragments, $286 \mathrm{bp}$ fragments and $412 \mathrm{bp}$ fragments after enzyme digestion (Figure 1).

\subsection{Polymorphism loci Allele and Genotype Frequency Distribution}

Checked by Hardy-Weinberg genetic laws of balance, the product of the 180 cases with RETN gene after PCR enzyme digestion, the genotype frequencies has reached its genetic balance, has a group representative.

After The Ear Ienzyme digestion, the product of RETN-420-C/G site electrophoresis obtained three genotypes: 1) The GG type: lacking of the Ear Ienzyme loci, only have $286 \mathrm{bp}$ fragments after enzyme digestion, which is liking the PCR products. 2) The CC type: containing the Ear Ienzyme loci, it has obtained the two fragments of $126 \mathrm{bp}$ fragments and $286 \mathrm{bp}$ fragments after enzyme digestion. 3) The GC type: miscellaneous type, it have obtained the three fragments of $126 \mathrm{bp}$ fragments, $286 \mathrm{bp}$ fragments and $412 \mathrm{bp}$ fragments after enzyme digestion. RETN-420-C/G loci polymorphism analysis, the allelic frequency and $\mathrm{CC} / \mathrm{GC}+\mathrm{GG}$ genotype distribution in T2DM group compared with ND group, the differences were statistically significant $(P<0.01)$. The allelic frequency and $\mathrm{CC} / \mathrm{GC}+\mathrm{GG}$ genotype distribution in T2DM complicated with macroangiopathy group compared with pure T2DM group, the differences also had statistical significance $(P<0.05)$.

The GC + GG genotype frequency in T2DM complicated with macroan giopathy group is significantly higher than the pure T2DM group $(P<0.05)$ (Figure 2 and Figure 3 ).

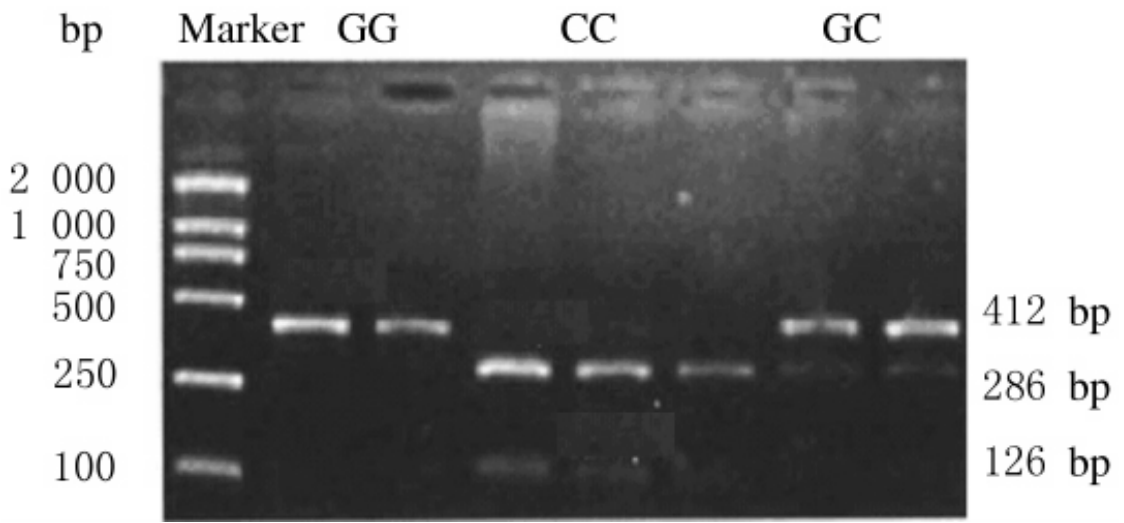

Figure 1. The electrophoretogram of three genotype fragments. 


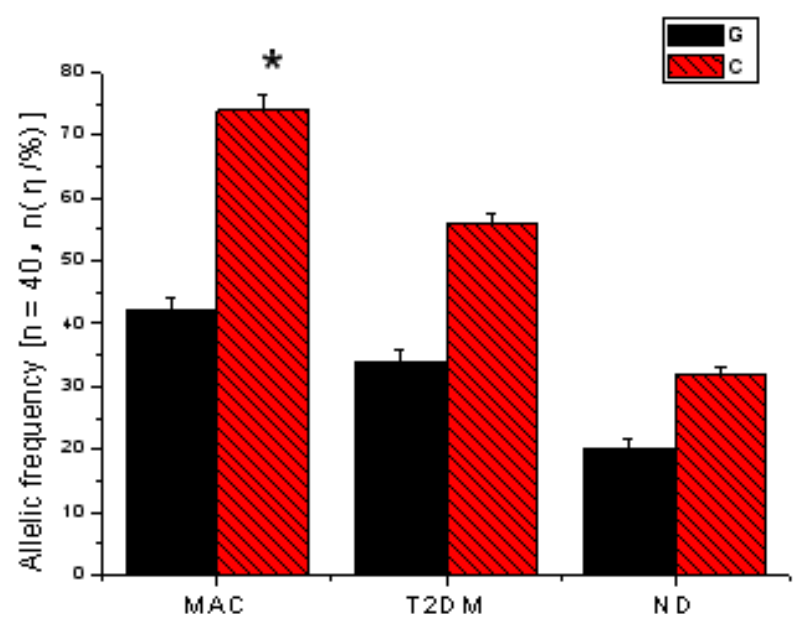

Figure 2. The comparisons of allelic frequency distribution of RETN-420C/G in various groups. ${ }^{\star} P<0.05$ compared with T2DM.

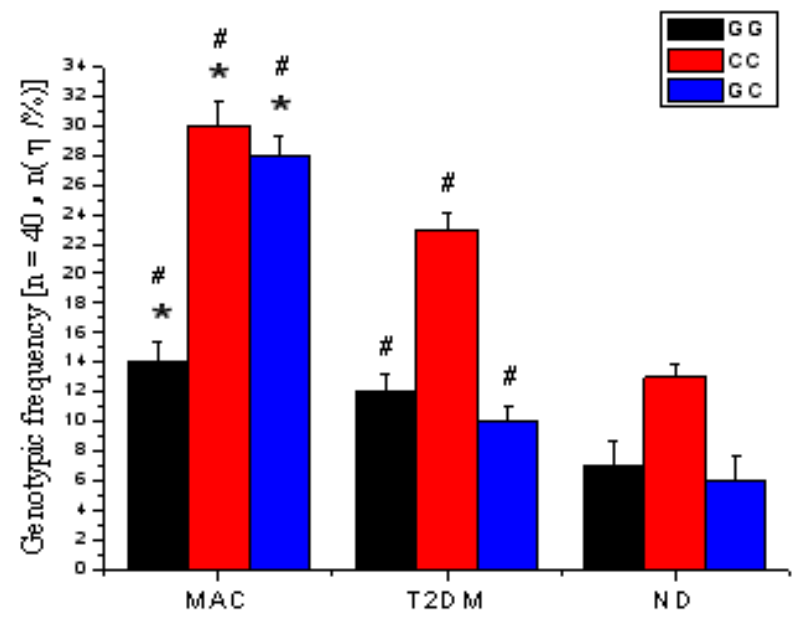

Figure 3. The comparisons of genotypic frequency distribution of RETN-420C/G in various groups. ${ }^{\star} P<0.05$ compared with T2DM group, $\# P<0.01$ compared with ND group.

\section{Discussion}

T2DM is a common more element and complex genetic disease, which has obvious heterogeneous. The genetic way and pathogenesis are very complex. The common role of environmental factors and genetic factors contributed to the occurrence of T2DM. At present, clinical evidence has found that, the incidence of T2DM between identical twins has high consistency, and the onset of familial aggregation is the norm. Especially the incidence of T2DM has huge differences between different RACES. It confirmed that T2DM is a hereditary disease. Studies have shown that, the onset of T2DM is caused by not a single genetic factor. The third generation of genetic polymorphism symbol SNPs is an important part that involved in insulin synthesis, storage and production [8]. In recent years, it has been applied in the studies associated with T2DM and candidate gene. At present, it has been identified that 2q37, 12q24 and 20q12 chain with T2DM, 
were named NIDDM1, NIDDM2 and NIDDM3 respectively.

RETN is secretory protein, which is existing in the plasma and rich in cysteine. Since found in 2001, the research both at home and abroad mainly focuses on the relationship between obesity and diabetes [9] [10]. RETN can adversely affect insulin action and play an important role in the occurrence of insulin resistance [11]. There are many cytology in vivo and in vitro experiments having established that RETN can cause damage to the insulin resistance and glucose tolerance [12] [13]. So it is think that RETN is the important link between obesity and T2DM. Whether RETN gene polymorphism was associated with T2DM has been the hot research in domestic in recent years. Studies of different RACES, different regions have different genetic loci, but the conclusion is inconsistent. It may be related to the following reasons: 1) The genetic differences between RACES; 2) Different geographical environment factors make the human body environment also corresponding variation; 3) The course, complications, and treatment of T2DM can influence genes expression in a different degree; 4) The means used to study are not enough to optimize; repeatability is poor, very difficult to get the verification conclusion on the same research topic; 5) Background sample selection is not ideal [14].

In conclusion, in this paper, the author thinks that The RETN-420C/G polymorphism has a correlation with the occurrence of T2DM complicated with macroangiopathy in Han population of northeast China.

\section{Acknowledgements}

This study was supported by the Jilin Science and Technology Project (No. 200905196 and No. 20150101148JC).

\section{References}

[1] UK Prospective Diabetes Study Group. (1997) Plasma Lipids and Lipoproteins at Diagnosis of NIDDM by Age and Sex: UKPDS. Diabetes Care, 20, 1683-1687.

[2] Steppan, C.M., Bailey, S.T. and Bhat, S. (2001) The Hormone Resistin Links Obesity to Diabetes. Nature, 409, 307-312. https://doi.org/10.1038/35053000

[3] Sentinelli, F., Romeo, S. and Arca, M. (2002) Human Resistin Gene, Obesity, Type 2 Diabetes: Mutation Analysis and Population Study. Diabetes, 51, 860-862. https://doi.org/10.2337/diabetes.51.3.860

[4] Ma, X.W., Warram, J.H. and Trischitta, V. (2002) Genetic Variants at the Resistin Locus and Risk of Type 2 Diabetes in Caucasians. Clin Endocrinol Metab, 87, 4407-4410. https://doi.org/10.1210/jc.2002-020109

[5] Engert, J.C., Vohl, M.C. and Williams, S.M. (2002) 5'flanking Varians of Resistin Are Associated with Obesity. Diabetes, 51, 1629-1634. https://doi.org/10.2337/diabetes.51.5.1629

[6] Thammakun, T., Laohasiriwong, W., Kraiklang, R. and Saengprajak, N. (2017) Association of $+62 \mathrm{G}>\mathrm{A}$ Polymorphism in the Resistin Gene with Type 2 Diabetes Mellitus among Thais: Case-Control Study. J Clin Diagn Res., 11, BC15-BC20.

[7] Houshmand-Oeregaard, A., Hansen, N.S., Hjort, L., Kelstrup, L., Broholm, C., Mathiesen, E.R., Clausen, T.D., Damm, P. and Vaag, A. (2017) Differential Adipokine 
DNA Methylation and Gene Expression in Subcutaneous Adipose Tissue from Adult Offspring of Women with Diabetes in Pregnancy. Clin Epigenetics, 13, 37. https://doi.org/10.1186/s13148-017-0338-2

[8] Chimienti, F., Favier, A. and Seve, M. (2005) ZnT-8, a Pancreatic Betacell-Specific Zinc Transporter. Biometals, 18, 313-317. https://doi.org/10.1007/s10534-005-3687-9

[9] Zayani, N., Hamdouni, H., Boumaiza, I., Achour, O., Neffati, F., Omezzine, A., Najjar, M.F. and Bouslama, A. (2017) Resistin Polymorphims, Plasma Resistin Levels and Obesity in Tunisian Volunteers. J Clin Lab Anal. https://doi.org/10.1002/jcla.22227

[10] Way, J.M., Gorgun, C.Z. and Tong, Q. (2001) Adipose Tissue Resistin Expression Is Severely Suppressed in Obesity and Stimulated by Peroxisome Proliferator-Activated Receptor Gamma Agonists. J Biol Chem, 276, 25651-25653. https://doi.org/10.1074/jbc.C100189200

[11] Zaidi, S.I. and Shirwany, T.A. (2015) Relationship of Serum Resistin with Insulin Resistance and Obesity. Jayub med coll abbottabad, 27, 552-555.

[12] Jiang, Y., Lu, L., Hu, Y., Li, Q., An, C., Yu, X., Shu, L., Chen, A., Niu, C., Zhou, L. and Yang, Z. (2016) Resistin Induces Hypertension and Insulin Resistance in Mice via a TLR4-Dependent Pathway. Sci Rep, 6, 22193. https://doi.org/10.1038/srep22193

[13] Wang, S.Y., Song, H.D. and Li, R.Y. (2003) Resistin Gene Overexpression in Adipose Tissue of SD Rats with High-Fat Diet and Its Correlation with Leptin and Insulin. Chin J Endocrinol Metab, 19, 191-193.

[14] Cheng, W., Yi, H.Z. and Ma, X.W. (2007) Single Mucleotide Polymorphism of Adiponectin Gene 45 Site in Patients with Type 2 Diabetes in the South of Henan Province. Journal of Zhengzhou University(Medical Sciences), 42, 1145-1147. 